\title{
CLEANING EFFICIENCY OF XP ENDOFINISHER R VERSUS SONIC IRRIGATION AFTER RETREATMENT (S.E.M IN VITRO STUDY)
}

\author{
Ahmed G. EL Soukary ${ }^{1 *}{ }_{B D S}$, Nihal A. Leheta ${ }^{2} P h D$, Nayera A. Mokhless ${ }^{3} P h D$.
}

\begin{abstract}
INTRODUCTION: Non-surgical endodontic treatment is the best way to re-establish sound periapical tissues after reinfection or inefficient treatment of a previously obturated teeth due to apical or coronal leakage. It requires regaining the accessibility to the root canal system by removing the initial root canal filling, more cleaning, and reobturation.

THE AIM OF THE STUDY: Is to compare the cleaning productivity of the XP Endo Finisher R (XPR) and the Endo Activator (EA) after retreatment using the scanning electron microscope (SEM).

MATERIAL AND METHODS: This study was performed on forty-five mesiobuccal canals of mandibular first molars. All teeth were obturated then retreated using D-Race rotary files. Teeth were haphazardly divided into three groups according to the cleaning method used: Group (1): XPR. Group (2): EA. Group (3): control group (no final cleaning). All the teeth were sectioned longitudinally and canal cleaning ability was assessed by the SEM. Data were statistically analyzed using Chi-Square and Kruskal Wallis tests.

RESULTS: Significant differences in the smear layer and debris removal between both XPR and EA groups and the control group were detected $(\mathrm{P}<0.05)$.

CONCLUSIONS: The XPR and the EA are both efficient in removing the debris and the smear layer after retreatment. Moreover, the XPR performed better than the EA. None of the investigated techniques were able to totally remove the filling material.
\end{abstract}

KEYWORDS: Retreatment, XP Endo Finisher R, Endo Activator, Scanning Electron Microscope.

${ }^{1}$ Resident dentist at the Conservative Dentistry Department, Faculty of Dentistry, Alexandria University, Alexandria, Egypt.

${ }^{2}$ Lecturer of Endodontics, Faculty of Dentistry, Alexandria University, Alexandria, Egypt.

${ }^{3}$ Assistant Professor of Endodontics, Conservative Dentistry Department, Faculty of Dentistry, Alexandria University, Egypt

*Corresponding author:

E-mail: ahmed.elsoukary@yahoo.com

\section{INTRODUCTION}

Complete removal of gutta-percha (GP) is a major goal in retreatment and it can be challenging and time-wasting (1). Non-surgical retreatment is the best way to re-establish sound periapical tissues after re-infection or inefficient treatment of a previously obturated teeth due to apical or coronal leakage (1). It requires regaining the accessibility to the root canal system by removing the initial root canal filling, more cleaning, and finally reobturation (2).

Many different devices and instrumentation techniques are available for GP removal, as the hand files, nickel-titanium (NiTi) rotary instruments (3), ultrasonic devices (4), and lasers (5). However, none of these techniques can totally remove the filling materials (6).

Recently, the XP Endo Finisher R (XPR) (FKG, Dentaire SA, La Chaux-de-Fonds, Switzerland), a new variation of the XP-endo Finisher file has been introduced. According to the manufacturer, the XPR file has tip diameter (ISO 30) larger than the XP-endo Finisher (ISO 25), making it slightly stiffer and more functional in the removal of the filling materials inside the canal, especially in the oval areas and the curved canals (7).

Despite the role of Instrumentation in retreatment, it is not able to totally remove the filling material from the root canal system. Irrigation is very essential as it can remove organic tissue, GP, debris, and sealer from the hard reached areas inside the root canal. Conventional irrigation system using an irrigation syringe is a widely used procedure, however, it cannot achieve complete cleanliness of the canal. Several irrigation activation systems were recently used to improve endodontic disinfection using manual agitation, lowspeed handpiece, sonic or subsonic energy, and ultrasonic systems (6).

The EndoActivator (EA) (Dentsply, Maillefer, Switzerland), a sonic based irrigation device that was introduced to improve the irrigation phase. It can activate the irrigation safely and agitate the fluid vigorously inside the canal. Thus it helps in the presence of EDTA in the removal of the debris and the smear layer especially from the teeth with curved roots (8).

The study aimed to compare the cleaning effectiveness of the XPR file and the EA after retreatment. The null hypothesis was that there is no statistically significant difference between the inspected techniques.

\section{MATERIALS AND METHODS \\ Teeth preparation}

The study was approved by the ethical committee at the faculty of dentistry, Alexandria University (IRBNO: 00010556-IORG0008839). Forty-five mesiobuccal canals of extracted mandibular first molar teeth were used in this study. 
Teeth collected from the oral maxillofacial surgery department were extracted because of periodontal reasons and were stored in saline until use. Only mandibular molars with non-fused roots and separate mesial canals (type IV Vertucci) (9) with moderate root curvature according to the long axis technique (10) were selected. Teeth were chosen approximately with an average length of $21 \mathrm{~mm}$.

Teeth were completely cleaned from calculus depositions or any soft tissue, then they were stored in isotonic saline. Teeth were inspected for any cracks by a magnifying lens. All teeth were radiographed in mesiodistal and buccolingual directions, to ensure similar canal morphology.

Access cavities were prepared using size 4 carbide round bur and Endo Z bur, then the pulp chambers were irrigated with $5.25 \%$ sodium hypochlorite solution. The working length (WL), was determined as being one millimeter short from the apical foramen. In order to avoid the expulsion of irrigant during irrigation, the apex was closed with nail varnish after retreatment was completed. Instrumentation started with hand stainless steel k-file \#10 to the full working length, then stainless steel k-file \#15 was used to the full length until being loose in the canal to achieve a glide path. Canals were prepared with Revo-S files (Micro-Mega, Besancon, France) using EDTA gel reaching a final preparation of SU file size \#25 taper 6\%, the canals were irrigated with a flush of ten milliliters of $17 \%$ EDTA solution and ten milliliters of sodium hypochlorite using a 27-gauge needle syringe then with a final flush of five milliliters distilled water, The canals were dried using paper points size \#25 then the canals were filled using GP cones size \#25 and resin sealer using lateral condensation technique. X-rays were done after obturation.

Retreatment was performed using D-race retreatment files (FKG, Dentaire SA, La Chaux-de-Fonds, Switzerland) (DR1 30/.10 and DR2 25/.04). DR1 was used for the removal of the root-filling material in the first millimeters of the coronal and straight part of the canal. Once access is cleared with the DR1, DR2 was used to reach the full WL then RevoS apical finisher size \#30 taper 6\% was used for final preparation (7). All canals were performed by the same administrator according to each manufacturer's recommendations.

A final radiograph was performed after retreatment to ensure that the filling material was removed. The teeth were then divided randomly into three equal groups of fifteen teeth each according to the method of the final cleaning.

\section{Group one: XPR files. \\ Group two: Endo activator system. \\ Group three: control group (No final cleaning). \\ Group one: XPR files}

After instrumentation with Revo-S apical finisher \#30 $6 \%$, XPR file introduced inside the canal according to the WL with a warm $5.25 \%$ sodium hypochlorite using a 27-gauge syringe with a flow rate five milliliters per minute. The file was used with fine insertion and withdrawal movements, the file was used with a torque controlled E CUBE Endo Motor (SAESHIN, Korea) operated at $800 \mathrm{rpm}$ and the torque was set to1 Ncm, according to manufacturer recommendation. The file was operated for one minute using smooth in and out movements. Finally the canal was flushed with a sterile five milliliters saline solution. Each file prepared only one canal before it was discarded (7).

\section{Group two: Endo activator system}

After instrumentation with Revo-S apical finisher \#30 $6 \%$, the EA was used. A 27-gauge syringe was used to fill the canal with a $5.25 \%$ sodium hypochlorite with a flow rate of five milliliters per minute. The EA system was used to activate the sodium hypochlorite solution for sixty seconds using a \#25 4\% polymer tip, the tip was placed two millimeters short from the WL of the canal. The vibrating tip was moved in vertical shots to optimize hydrodynamic phenomena, finally, the canal was flushed with a five milliliters saline solution (6).

\section{Preparation of the specimens}

In order not to contaminate the canal, master GP cone (Micro-Mega, Besancon, France) was put in the canal. The crown of each tooth was removed then the distal and the mesial roots were separated using a diamond disk. Specimens were thoroughly cleaned from dentin powder using a gauze. Teeth were carefully cut longitudinally with a diamond disk (Brassler, USA) by making vertical grooves, on the mesial and distal surfaces of the root, then the roots were split using chisel and mallet (Dentalis, USA) (11).

Scanning electron microscope assessment

After specimens preparation by dehydration and mounting on aluminum stubs. Specimens were examined under the scanning electron microscope (SEM) (JEOL, JSM 5300, Tokyo/ JAPAN) at 4000× magnification. Three photomicrographs were taken for each specimen (apical, middle, and coronal third) for comparative purposes (11).

Finally debris and smear layer analysis were done based on Hulsmann et al five grade scoring system (12).

The presence of debris was evaluated by the following scores; score 1: Clean root canal wall, only few small debris particles. Score 2: Few small agglomerations of debris. Score 3: Many agglomerations of debris covering less than $50 \%$ of the root canal wall. Score 4: More than $50 \%$ of the root canal wall covered by debris. Score 5: Complete or nearly complete root canal wall covered by debris.

The presence of smear layer was also evaluated by a five-grade scoring system as follows; score 1: No smear layer, dentinal tubules open. Score 2: Small amount of smear layer, some dentinal tubules open. Score 3: Homogenous smear layer covering the root canal wall, only few dentinal tubules open. Score 4: Complete root canal wall covered by a homogenous smear layer, no open dentinal tubules. Score 5: Heavy, non-homogenous smear layer covering the complete root canal wall.

Representative photomicrographs of debris and smear layer of each group at the three segments are shown in (Figure 1).

\section{Inter-examiner and intra-Examiner reliability tests}

The intra-reliability test was done by the researcher as scores were reevaluated two weeks later. Scoring was made by three observers to increase the reliability of the results obtained. Scores of the researcher and the supervisors were collected, tabulated and intra-examiner and inter-examiner reliability tests were assessed using the Kappa test (13). 

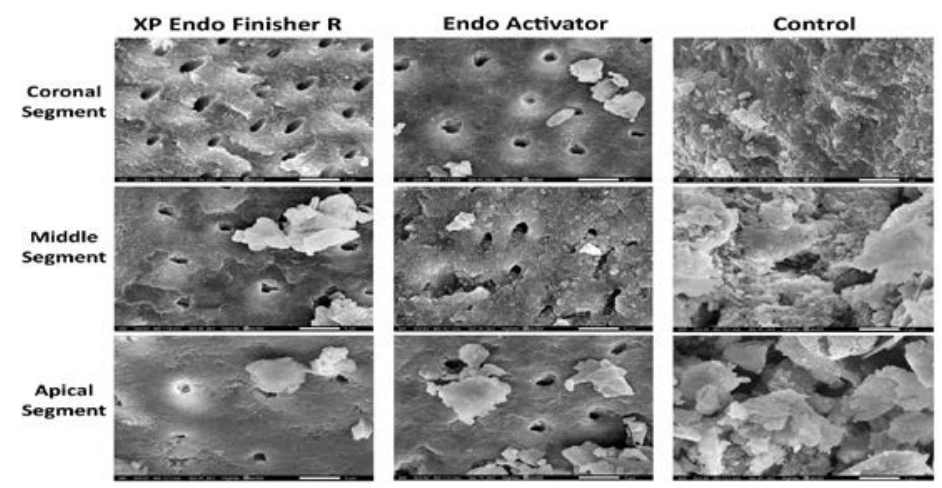

Figure (1): Showing photomicrographs of debris and smear layer of the tested groups in root canal segments.

\section{Statistical analysis of the data}

Data were checked for any error during data entry. Kruskal Wallis test was utilized to compare between the groups regarding the smear layer scores and debris scores. The distribution of the scores was analyzed using the Chi-Square test. The level of significance was adjusted at $p$-value $\leq 0.05$. Data were analyzed utilizing IBM SPSS version 25.

\section{RESULTS}

Comparison of smear layer scores among XPR, EA, and the control groups

None of the groups showed complete smear layer removal. There were significant differences in smear layer removal between both the XPR and the EA groups and the control group. Moreover, the XPR performed better than the EA.

In the XPR group, the smear layer was more efficiently cleaned in the coronal segment than the other segments, with no significant difference between them. (Table 1)

In the EA group, the smear layer was more efficiently cleaned in the coronal and the middle segments, with no significant difference between them. Moreover, the coronal segments were cleaner than the apical segments with a significant difference between them and the smear layer removal was significantly better in the middle segment than the apical segment. (Table 1)

In the control group, all segments showed an equal amount of smear layer with no significant difference between the coronal and the middle segments. Furthermore, there was a significant difference between the coronal and apical segments and between the apical and middle segments. (Table 1).

\section{Comparison of debris scores among XPR files, EA, and the control groups}

None of the groups showed complete removal of the debris. The control group showed complete coverage of their canal walls with debris with a significant difference between the other groups. Moreover, the XPR performed better than the EA.
Table 1: Comparison of smear layer scores among XPR, EA and the control groups

\begin{tabular}{|c|c|c|c|c|c|}
\hline & & $\begin{array}{c}\text { XP Endo } \\
\text { Finisher R } \\
\text { files } \\
(\mathrm{n}=15) \\
\end{array}$ & $\begin{array}{l}\text { Endo- } \\
\text { Activator } \\
(\mathrm{n}=15)\end{array}$ & $\begin{array}{l}\text { Control } \\
(n=15)\end{array}$ & $\begin{array}{l}P \\
\text { value }\end{array}$ \\
\hline \multirow[t]{2}{*}{ Coronal } & Median & $1^{\mathrm{a}}$ & $3^{b}$ & $5^{c}$ & $<0.000$ \\
\hline & IQR & $1-2$ & $2-3$ & $5-5$ & $1^{*}$ \\
\hline \multirow[t]{2}{*}{\begin{tabular}{|l|} 
Middle \\
\end{tabular}} & Median & $3^{a}$ & $3^{b}$ & $5^{c}$ & $<0.000$ \\
\hline & IQR & $3-3$ & 3-4 & - & $1 *$ \\
\hline \multirow[t]{2}{*}{ Apical } & Median & $4^{\mathrm{a}}$ & $4^{\mathrm{a}}$ & $5^{b}$ & $<0.000$ \\
\hline & IQR & $3-4$ & $3-4$ & - & $1 *$ \\
\hline
\end{tabular}

differences between the groups

* Statistically significant difference at $p$ value $\leq 0.05$

IQR: Inter-quartile range

In the XPR group, all segments were equally cleaned from debris with no significant difference between them. (Table 2)

In the EA group, debris was more efficiently cleaned in the coronal segment than the other segments, with a significant difference between them. Moreover, there was no significant difference between the apical and middle segments. (Table 2)

In the control group, all segments showed an equal amount of debris covering the canal walls with a significant difference between the coronal segment and both the middle and the apical segments. There was no significant difference between the middle and the apical segments. (Table 2)

Table 2: Comparison of debris scores among XPR, EA and the control groups

\begin{tabular}{|c|c|c|c|c|c|}
\hline & & $\begin{array}{c}\text { XP Endo } \\
\text { Finisher R } \\
\text { files } \\
(n=15)\end{array}$ & $\begin{array}{l}\text { EndoActivator } \\
\quad(\mathrm{n}=15)\end{array}$ & $\begin{array}{l}\text { Control } \\
(\mathrm{n}=15)\end{array}$ & $P$ value \\
\hline \multirow[t]{2}{*}{ coronal } & Median & $2^{\mathrm{a}}$ & $2^{\mathrm{a}}$ & $5^{\mathrm{b}}$ & \multirow{2}{*}{$<0.0001^{*}$} \\
\hline & IQR & $2-2$ & $2-2$ & 5-5 & \\
\hline \multirow[t]{2}{*}{ Middle } & Median & $2^{\mathrm{a}}$ & $3^{\mathrm{b}}$ & $5^{c}$ & \multirow{2}{*}{$<0.0001^{*}$} \\
\hline & IQR & $2-3$ & $2-4$ & $5-5$ & \\
\hline \multirow[t]{2}{*}{ Apical } & Median & $2^{a}$ & $3^{\mathrm{b}}$ & $5^{c}$ & \multirow{2}{*}{$<0.0001^{*}$} \\
\hline & IQR & $2-3$ & $2-3$ & - & \\
\hline
\end{tabular}

differences between the groups

*Statistically significant difference at $p$ value $\leq 0.05$

IQR: Inter-quartile range

\section{DISCUSSION}

Non-surgical endodontic retreatment main objective is to re-establish sound periapical tissues and obtain predictable success through complete removal of the old root filling material, regaining $\mathrm{WL}$, more cleaning, and finally reobturating the root canal. Nickel-titanium rotary and reciprocating files are not sufficient to totally clean the root canal walls from sealer and GP remnants (14-16). As a result, additional techniques were invented specifically to upgrade the expulsion of existing root filling materials. Thus, this study was conducted to evaluate the cleaning efficiency of the XPR file and the EA system using the SEM.

The XPR has been selected in this work as it has been 
recently introduced to optimize the cleaning efficiency during root canal retreatment and needs further investigations. Its sickle shape and its expansion ability allow it to access and clean the impossible reached areas. It also has a tip diameter (ISO 30) larger than the XP-endo Finisher (ISO 25), making it somewhat stiffer and more productive within the removal of the root canal fillings materials, particularly within the oval areas and the curved canals (7). The sonic system was also selected in this study to evaluate if the EA ability to agitate the irrigants within the canal can be more effective in the removal of the root filling materials, in addition to its hydrodynamic phenomenon (6).

In the present study Mesio-buccal canals of mandibular molars with moderate curvature were preferred to be used as it is more challenging and to prove the ability of the XPR to clean curved canals as suggested by the manufacturer.

In the current work the D-race retreatment files was used before using the XP Endo Finisher R file following Alzuabi et al (2018) (7) as it was very hard to remove the gutta-percha and the resin sealer by using the XP Endo Finisher $\mathrm{R}$ file alone.

In the current study, the last file used after retreatment was Revo-S apical finisher \#30 6\% to suit the apical diameter of the XPR file ISO \#30/0.00. Retreatment was done without the aid of solvents, despite the manufacturer's recommendation of using solvents when using the XPR. It was preferred not to use these materials as it has a cytotoxic effect, furthermore, solvents may also cause the adherence of a softened layer of GP on the root canal walls. Moreover Campello et al (2019) (17) highlighted the fact that the use of solvent did not improve the removal of filling material using the XPR.

In the present study the tip diameter of the XP Endo Finisher R file was ISO \#30 while the tip diameter of the endo activator was ISO \#25 so the Revo-S apical finisher size \#30 taper 6\% was used for final preparation in all groups which might compensate this limitation to a certain limit. It's worth knowing that the XP Endo Finisher $\mathrm{R}$ depends on the mechanical action as the instrument has to touch and dislodge the filling material from the canal walls. On the other hand the difference in size of Endoactivator tip has no effect as the Endoactivator passively activate the irrigation inside the canal with no attempt to contact the canal walls depending on the hydrodynamic theory $(6,7)$.

In this study, the SEM was selected following Dadresanfar et al (2012) (18) and Alturaiki et al (2015) (8) as it is the most used method because of its ability to evaluate more than one specimen at the same time with a high resolution. Also it can assess the dentinal tubules even in the presence of smear layer. Furthermore it helps in debris and smear layer evaluation based on a numeric scoring system. On the contrary other studies used the stereomicroscope as Ozyurek et al (2016) (11) and the cone-beam computed tomography (CBCT) images as Khedmat et al (2017) (19). The nondestructive micro CT analysis is the gold standard method. .Unfortunately it wasn't used in this study as it is not available in Egypt.

In the present study the null hypothesis was rejected as on comparing the results there were significant differences between both XPR and the EA and the control group in all segments in the smear layer and debris removal. The XPR was more efficient in cleaning the root canals after retreatment than the EA. This was in agreement with Talal et al (2018) (20) who compared the XPR with the EA in the removal of the calcium hydroxide and found that the XPR was more efficient. De-Deus et al (2019) (4) also showed that the XPR is better in retreatment than Passive ultrasonic irrigation (PUI).

The efficiency of the XPR was also demonstrated previously by Silva et al (2018) (21) and Machado et al (2019) (22). They found that the XPR efficiently removed the filling material at all root canal segments. It is worth mentioning that previous studies compared the XPR with instrumentation files as the Self-Adjusting File, TRUShape, and XP-endo Finisher system not with irrigation devices.

On the other hand result of the current work disagree with Nair et al (2009) (6) who evaluated the efficiency of the EA and the F file after instrumentation and reported that the EA was more efficient. However it is relevant to note that $\mathrm{F}$ file is an irrigation agitation file not a finisher file. Alturaiki et al (2015) (8) also evaluated the effectiveness of the EA with the EndoVac (Negative pressure irrigation system) and ProUltra (Ultrasonic continuous irrigation system) and reported that the EA removed the calcium hydroxide better than the other systems in all root segments. To the best of our knowledge, there are no studies in the literature that have compared the efficiency of the XPR and the EA after retreatment.

This result could be attributed to the features of XPR which make it stiffer and also more efficient in the removal of debris adhering to the root canal walls. Moreover, the mechanical action allows the instrument's tip to eject the debris and the smear layer stuck on the canal walls, so they can be removed during irrigation (4).

In this work the EA was also efficient in the removal of the filling material. This might be explained by the EA features as the tip vibrates at a speed of 10,000 rpm which generates intracanal waves creating negative pressure that causes liquid diffraction. Bubbles are generated that expand and become unstable, then collapse and promote explosions. Explosions radiate shock waves that could have promoted deep lateral cleaning. The EA system has the ability to upgrade the infiltration, circulation, and the irrigants flowing into the inaccessible areas (8).

In this work, XPR removed the debris in all segments significantly better than the EA, the same applied to the removal of the smear layer except for the apical third which showed no significant differences between them. This could be explained by the fact that it has the ability to expand and contract up to six millimeters in diameter or one hundredfold when compared with a standard Instrument of the same size. Its sickle shape and its expansion ability permit it to approach and clean the impossible reached areas (17).

Direct comparison of the results among the studies was difficult due to several reasons; first of all, the selection of teeth which varied between central incisors, oval canals in premolars, and curved canals in molars. Moreover, the use of different techniques of instrumentations before and after 
retreatment. In addition to the difference in the size of the apical diameter reached before the retreatment procedures. The type of sealer used for obturation also varied among studies. In the present work, resin sealer was used and it was challenging and very difficult in removal. Furthermore the method of assessment of smear layer and debris removal was variable among the studies using either SEM, stereomicroscope, or CBCT. Moreover, the difference in the magnification power, varied between $5000 \times$ and $500 \times$, additionally, the qualitative analysis of the different scoring methods used.

\section{CONCLUSION}

The XPR and the EA are efficient in the removal of debris and smear layer after retreatment. The XPR is promising in retreatment and performed better than the EA. None of the investigated techniques totally removed the filling material.

\section{CONFLICT OF INTREST} interest.

The authors declare that they have no conflicts of

\section{REFERENCES}

1. Yadav P, Bharath MJ, Sahadev CK, Makonahalli Ramachandra PK, Rao Y, Ali A, et al. An in vitro CT comparison of gutta-percha removal with two rotary systems and hedstrom files. Iran Endod J. 2013;8:59-64.

2. Mali S, Patil A, Hegde D, Jaiswal H, Saoji H, Edake DN. Efficacy of rotary and hand instrument in removing guttapercha and sealer from root canals of endodontically treated teeth. J Contemp Dent Pract. 2018;19:964-8.

3. Bedier MM, Hashem AAR, Hassan YM. Improved dentin disinfection by combining different-geometry rotary nickel-titanium files in preparing root canals. Restor Dent Endod. 2018;43:e46.

4. De-Deus G, Belladonna FG, Zuolo AS, Cavalcante DM, Carvalhal JCA, Simões-Carvalho $\mathrm{M}$, et al. XP-endo Finisher R instrument optimizes the removal of root filling remnants in oval-shaped canals. Int Endod J. 2019;52:899-907.

5. dönmez özkan H, Kaval M, Özkan G, Özer S. Efficacy of two different nickel-titanium rotary systems in retreatment procedure with or without laser-activated irrigation: An in vitro study. Photomed Laser Surg. 2019;37:495-9.

6. Nair U, Natera M, Koscso K, Pillai P, Varella C, Pileggi R. Comparative evaluation of three different irrigation activation on debris removal from root canal systems. J. Dent. Sci.. 2011;57.

7. Alzuabi MA, Abiad R. Ability of of XP-Endo Finisher and $\mathrm{XP}-$ Endo Finisher-R in removal of debris from the root canal walls after retreatment: An in-vitro study. Int Arab J Dent. 2018;9:61-4.

8. Alturaiki S, Lamphon H, Edrees H, Ahlquist M. Efficacy of 3 different irrigation systems on removal of calcium hydroxide from the root canal: a scanning electron microscopic study. J Endod. 2015;41:97-101.

9. Vertucci FJ. Root canal anatomy of the human permanent teeth. Oral Surg Oral Med Oral Pathol. 1984;58:589-99.
10. Günday M, Sazak H, Garip Y. A comparative study of three different root canal curvature measurement techniques and measuring the canal access angle in curved canals. J Endod. 2005;31:796-8.

11. Ozyurek T. Comparison of the smear layer removal ability of four different final activation techniques after retreatment procedures: a SEM investigation. Turk Endod J. 2017;2:10-6.

12. Srinivasan R, Ashwathappa GS, Junjanna P, Bhandary S, Aswathanarayana RM, Shetty A. Evaluation of smear layer removal from ultrasonically prepared retrocavities by three agents. J Conserv Dent. 2014;17:330-4.

13. McHugh ML. Interrater reliability: the kappa statistic. Biochem Med (Zagreb). 2012;22:276-82.

14. Hammad M, Qualtrough A, Silikas N. Threedimensional evaluation of effectiveness of hand and rotary instrumentation for retreatment of canals filled with different materials. J Endod. 2008;34:1370-3.

15. Unal GC, Kaya BU, Taç AG, Keçeci AD. A comparison of the efficacy of conventional and new retreatment instruments to remove gutta-percha in curved root canals: an ex vivo study. Int Endod J. 2009;42:344-50.

16. Ersev H, Yilmaz B, Dinçol ME, Dağlaroğlu R. The efficacy of ProTaper Universal rotary retreatment instrumentation to remove single gutta-percha cones cemented with several endodontic sealers. Int Endod J. 2012;45:756-62.

17. Campello AF, Almeida BM, Franzoni MA, Alves FRF, Marceliano-Alves MF, Rôças IN, et al. Influence of solvent and a supplementary step with a finishing instrument on filling material removal from canals connected by an isthmus. Int Endod J. 2019;52:716-24.

18. Dadresanfar B, Iranmanesh M, Mohebbi P, Vatanpour M. Efficacy of two rotary NiTi instruments in removal of resilon/epiphany obturants. Iran Endod J. 2012;7:183.

19. Khedmat S, Azari A, Shamshiri AR, Fadae M, Bashizadeh Fakhar H. Efficacy of ProTaper and Mtwo Retreatment Files in Removal of Gutta-percha and GuttaFlow from Root Canals. Iran Endod J. 2016;11:184-7.

20. Talal T, al-zaka I. Efficacy of XP-endo Finisher, XPendo Finisher R, CanalBrush and endoactivator in the removal of intracanal medicament (An in vitro study). Int. J. Sci.. 2018;8:919-28.

21. Silva EJNL, Belladonna FG, Zuolo AS, Rodrigues E, Ehrhardt IC, Souza EM, et al. Effectiveness of XP-endo Finisher and XP-endo Finisher R in removing root filling remnants: a micro-CT study. Int Endod J. 2018;51:86-91.

22. Machado AG, Guilherme BPS, Provenzano JC, Marceliano-Alves MF, Gonçalves LS, Siqueira JF, et al. Effects of preparation with the Self-Adjusting File, TRUShape and XP-endo Shaper systems, and a supplementary step with XP-endo Finisher R on filling material removal during retreatment of mandibular molar canals. Int Endod J. 2019;52:709-15. 